\title{
Improving the detection rate of early gastric cancer requires more than open access gastroscopy: a five year study
}

\author{
Z Suvakovic, M G Bramble, R Jones, C Wilson, N Idle, J Ryott
}

\begin{abstract}
Backgroundlaims-To explore the reasons why patients with gastric cancer continue to present with advanced disease despite open access gastroscopy.

Patients-All patients diagnosed with gastric cancer between 1 August 1989 and 31 July 1994.

Methods-A retrospective study of the presentation of gastric cancer in South Tees; patients were diagnosed at open access gastroscopy or referred through conventional channels. Primary care records of 81 patients dying between 1991 and 1995 were analysed for previous symptoms, investigations, and antisecretory drug therapy. Findings were compared with 200 age and sex matched controls.

Results-The overall incidence of earlier stage gastric cancer remains low at $13 \%$. Diagnostic delay occurs in both primary and secondary care due to a high incidence of previous dyspepsia and investigation. One in six patients had been previously investigated in the three years prior to diagnosis, the majority of whom were on antisecretory drugs.

Conclusions-Early gastric cancer remains rare in South Tees health district. Advantages of open access gastroscopy appear to be compromised by delayed referral to hospital and failure of endoscopists to recognise the early disease; either they are unaware of its appearance or prior treatment with an $\mathrm{H}_{2}$ receptor antagonist masks the disease by allowing mucosal healing.

(Gut 1997; 41: 308-313)
\end{abstract}

Keywords: gastric cancer; open access gastroscopy; primary care

Gastric cancer remains a common gastrointestinal malignancy in the Western world ${ }^{1}$ with most patients presenting at a late stage of the disease. $^{2}$ An increase in the incidence of early gastric cancer (EGC) has been reported from several centres ${ }^{3-5}$ and partly attributed ${ }^{3}$ to the availability of open access gastroscopy (OAG). It is unclear why some units seem to achieve a higher incidence of early disease compared with other centres. ${ }^{2}$ In theory OAG should only accelerate the diagnosis by a few weeks or months ${ }^{6}$ and by itself would not account for the higher incidence of EGC reported from some centres. On the other hand, lowering the referral threshold for investigating "benign" symptoms might increase the detection rate of EGC if gastroscopy is freely available to general practitioners. Surgical cure is unlikely once worrying symptoms (dysphagia, anaemia, and weight loss) develop ${ }^{7}$ and such patients are less likely to be referred to an open access service. ${ }^{8}$

We have been offering unrestricted OAG to general practitioners since 1 August 1989, all details being recorded in a separate database for the purposes of audit and research. The aims of this study were to compare patients diagnosed as having gastric cancer at OAG with patients referred through other channels (mainly outpatient clinics) to see whether OAG did pick up more early tumours, and to analyse the effect of this on whole district figures. The study also attempted to analyse whether late stage disease was more common in patients with a longer history of symptoms prior to referral.

\section{Methods}

All patients diagnosed as having gastric cancer at OAG and resident within South Tees health district (population 295 000) were identified from the computer held database for the five years to 31 July 1994. These data were cross checked with pathology records at the end of the five year period of study to ensure that patients with malignant gastric ulcers were not missed. In addition all other patients diagnosed as having gastric cancer during the same period and resident in South Tees were also identified from the pathology records to allow a retrospective analysis of presenting symptoms, general practitioner diagnosis, hospital records, operative findings, and histological findings in both groups. The tumours were staged by two independent pathologists using the TNM classification. $^{9}$

The primary health care records of 81 of these patients dying from gastric cancer in the years 1991-95 and held by the Family Health Services Authority were analysed for previous dyspeptic symptoms, investigations, and treatment. The findings were compared with 200 age and sex matched controls dying from nonmalignant causes during the same period.
Accepted for publication 7 May 1997 
TABLE 1 Gastric cancer cases $(n=181)$ diagnosed from 1989 to 1994

\begin{tabular}{lll}
\hline & \multicolumn{2}{l}{ Type of referral } \\
\cline { 2 - 3 } & Clinic & OAG \\
\hline No. of patients & 142 & 39 \\
M:F ratio & $86: 56$ & $25: 14$ \\
Mean age (y) & $68 / 72$ & $67 / 57$ \\
High gastric & 89 & 31 \\
Low gastric & 39 & 7 \\
Extensive & 14 & 1 \\
\hline
\end{tabular}

STATISTICS

Where appropriate, the $\chi^{2}$ test was performed.

\section{Results}

During the five years of study, 181 cases of gastric cancer were identified of whom 39 patients were diagnosed following OAG (out of 6633 gastroscopies); 142 were diagnosed following clinic referral or emergency admission (eight cases). The two groups were similar in terms of age and sex distribution (table 1). The overall incidence of early gastric cancer (EGC) was $4 \%$ with a further $9 \%$ identified as having stage I disease.

OPEN ACCESS REFERRALS

In total, $21.1 \%(9 / 39)$ of patients diagnosed through OAG had EGC or stage I disease compared with $10.6 \%(15 / 142)$ of patients diagnosed through conventional channels. This difference failed to reach significance $\left(\chi^{2}=3.149 ; \quad \mathrm{p}=0.05-0.1\right)$. No differences emerged related to tumour site with $70 \%$ of cancers being lying above the incisura and below $35 \mathrm{~cm}$ in both groups.

CLINIC REFERRALS

Within the clinic referral group there was a non-significant trend towards more high gastric cancer in the surgical clinics compared with those referred to a medical gastroenterologist. Excluding 14 patients with extensive disease, 55/72 patients referred to surgery had high gastric cancer compared with 34/56 patients referred to medical clinics $\left(\chi^{2}=2.951\right.$; $\mathrm{p}=0.05-0.1$ ). Low gastric cancer (antrum and pylorus) showed the opposite trend with 17 patients referred to surgery and 22 to medical clinics.

SYMPTOMS

Worrying symptoms (dysphagia, anaemia, or weight loss) were present in $85 \%$ (120 patients) of those referred to clinic compared with only $51 \%$ (20 patients) of those referred for open access gastroscopy $\left(\chi^{2}=17.43 ; \mathrm{p}<0.001\right)$. There was no overall difference in worrying symptoms between surgical and medical clinics except for dysphagia which was more common in the surgical group (49 v 16 patients; $\left.\chi^{2}=16.774 ; \mathrm{p}<0.001\right)$.

GENERAL PRACTITIONER DIAGNOSIS

Gastric cancer, as specified on the referral form, was suspected in only six patients referred for OAG despite the fact that 20 patients had one or more worrying symptoms.
General practitioner diagnosis was less clear from referral letters to clinic, but from the details given gastric cancer was a possibility in at least 49 patients $\left(\chi^{2}=4.42 ; \mathrm{p}<0.05\right)$.

DELAY IN DIAGNOSIS

No differences emerged between OAG and clinic based referrals although not all cancers were diagnosed at the first gastroscopy (21 were not). Table 2 presents details of these patients. Six cancers were missed altogether and eight were diagnosed histologically when the endoscopic findings indicated benign disease.

Only five patients were diagnosed as having gastric ulcer disease, the remainder having a spectrum of minor diseases such as gastritis. Excluding those patients with suspected malignancy but benign or inconclusive histology, $12 \%$ had a delay in diagnosis ranging from three weeks to 12 months. Patients diagnosed on histology alone were more likely to have earlier disease than those where malignancy was diagnosed at gastroscopy. Although the numbers are small, three of the eight patients diagnosed by biopsy alone had EGC or stage I disease.

\section{PRIMARY CARE RECORDS}

The primary care records of 81 patients dying from gastric cancer in the years 1991-95 and diagnosed during the five year period of study (that is, same cohort of patients) were scrutinised for previous dyspeptic symptoms, excluding those leading up to referral and diagnosis. In addition records were examined for previously prescribed antisecretory or antacid therapy as well as previous investigation such as barium meal examination or gastroscopy. Figure 1 presents the results which indicate a lifetime prevalence of dyspepsia necessitating a consultation with the general practitioner in $73 \%$. This compares with only $22 \%$ of the 200 age and sex matched controls dying of non-malignant disease from the same practices $\left(\chi^{2}=56.23 ; \mathrm{p}<0.001\right)$. Twenty two patients had no previous history of dyspepsia. Of 59 patients with a previous history of dyspepsia, 19 had not been investigated. In only 20 patients was the diagnosis suspected at the time of referral. Just under half the patients had been investigated at some time in the past (40 patients). Figure 2 shows duration of symptoms.

\section{DELAY IN DIAGNOSIS}

The average time between the onset of current symptoms and diagnosis was 32 weeks, equally split between the time the patient took to consult the general practitioner and the time the general practitioner took to refer the patient to hospital.

PREVIOUS BARIUM MEAL INVESTIGATION

Thirty patients had previously had a barium meal examination, three to 42 years prior to the diagnosis of gastric cancer. The majority had been investigated more than 10 years previously $(75 \%)$. Only two patients had been 
TABLE 2 OAG versus clinic based referrals

\begin{tabular}{|c|c|c|c|c|c|c|c|c|c|}
\hline Patient & Year & Investigation & Diagnosis & Treatment & Investigation & Finding & Diagnosis & Site & Delay \\
\hline WA & 1949 & Barium meal & $\mathrm{DU}$ & No & No & & 1991 & High & No \\
\hline DB & 1949 & Barium meal & DU & Yes & No & & 1991 & High & No \\
\hline DB & 1955 & Barium meal & GU & No & No & & 1991 & High & No \\
\hline FJ & 1955 & Barium meal & DU & Yes & No & & 1992 & High & No \\
\hline $\mathrm{RM}$ & 1957 & Barium meal & DU & Yes & 1990 OGD & NAD & 1991 & High & Yes $(1 \mathrm{y})$ \\
\hline DL & 1957 & Barium meal & DU/GORD & Yes & No & & 1992 & High & No \\
\hline $\mathrm{JP}$ & 1969 & Barium meal & $\mathrm{DU} / \mathrm{GU} / \mathrm{EGC}$ & Yes & 1991 OGD & GU & 1991 & Low & No \\
\hline SB & 1970 & Barium meal & NAD & Yes & No & & 1991 & Low & No \\
\hline PD & 1971 & Barium meal & GU & No & No & & 1992 & EGC & No \\
\hline JC & 1971 & Barium meal & GORD & No & No & & 1992 & Low & No \\
\hline JC & 1971 & Barium meal & NAD & No & 1990 OGD & GU & 1992 & High & Yes $(2 \mathrm{y})$ \\
\hline $\mathrm{AC}$ & 1977 & Barium meal & NAD & Yes & 1985 OGD & NAD & 1992 & High & No \\
\hline $\mathrm{AD}$ & 1978 & Barium meal & GU & No & 1986 OGD & NAD & 1991 & High & Possible (5 y) \\
\hline MJ & 1978 & Barium meal & DU & Yes & No & & 1991 & Low & No \\
\hline ED & 1979 & Barium meal & GU & No & 1981 OGD & NAD & 1991 & Low & No \\
\hline NS & 1979 & Barium meal & DU & Yes & No & & 1992 & High & No \\
\hline $\mathrm{RB}$ & 1981 & Barium meal & GU & Yes & 1981 OGD & GU & 1992 & High & No \\
\hline $\mathrm{AK}$ & 1981 & Barium meal & GORD & Yes & 1985 OGD & GORD & 1992 & High & No \\
\hline MR & 1982 & Barium meal & GU/ECG & Yes & No & & 1991 & Low & No \\
\hline $\mathrm{RC}$ & 1983 & Barium meal & GU & Yes & 1991 OGD & GU & 1992 & High & Yes $(1 \mathrm{y})$ \\
\hline $\mathrm{JH}$ & 1986 & Barium meal & NAD & No & No & & 1992 & Low & No \\
\hline $\mathrm{FF}$ & 1987 & Barium meal & NAD & Yes & No & & 1990 & Low & Yes $(3 \mathrm{y})$ \\
\hline ES & 1989 & Barium meal & NAD & Yes & No & & 1992 & High & Yes $(3 \mathrm{y})$ \\
\hline $\mathrm{CB}$ & 1981 & Barium meal & NAD & Yes & No & & 1993 & High & No \\
\hline WW & 1976 & Barium meal & NAD & Yes & 1980 Barium meal & GU & 1992 & High & No \\
\hline RL & 1972 & Barium meal & DU & No & 1980 OGD & NAD & 1993 & High & No \\
\hline $\mathrm{RR}$ & 1959 & Barium meal & NAD & No & 1970 Barium meal & DU & 1992 & High & No \\
\hline EB & 1980 & Barium meal & NAD & No & No & & 1993 & High & No \\
\hline $\mathrm{RB}$ & 1986 & Barium meal & NAD & Yes & No & & 1992 & Low & No \\
\hline JW & 1974 & Barium meal & NAD & Yes & 1975 Barium meal & NAD & 1993 & High & No \\
\hline CG & 1992 & OGD & DU & Yes & No & & 1992 & Low & Yes (6 months) \\
\hline $\mathrm{JR}$ & 1985 & OGD & GORD & Yes & 1992 OGD & EGC & 1992 & EGC & No \\
\hline MW & 1988 & OGD & DU & Yes & 1991 OGD & NAD & 1992 & High & Yes (18 months) \\
\hline $\mathrm{LH}$ & 1988 & OGD & NAD & Yes & No & & 1992 & High & Possible (4 y) \\
\hline MW & 1988 & OGD & NAD & Yes & 1990 OGD & Suspicious & 1990 & Low & Yes $(2 \mathrm{y})$ \\
\hline GN & 1989 & OGD & GU & Yes & 1990 OGD & $\mathrm{GU}$ & 1990 & High & Yes (2 y) \\
\hline PG & 1989 & OGD & GU & Yes & 1991 OGD & GU & 1991 & High & Yes $(3 \mathrm{y})$ \\
\hline $\mathrm{FH}$ & 1990 & OGD & NAD & Yes & No & & 1992 & High & Yes $(2 \mathrm{y})$ \\
\hline $\mathrm{JT}$ & 1989 & OGD & NAD & Yes & No & & 1990 & High & Yes $(1 \mathrm{y})$ \\
\hline FG & 1991 & OGD & GU & Yes & 1992 OGD & GU & 1992 & Low & Yes $(1 \mathrm{y})$ \\
\hline
\end{tabular}

DU, duodenal ulcer; GU, gastric ulcer; GORD, gastro-oesophageal reflux disease; NAD, no abnormality detected; OGD, full gastrointestinal endoscopy. Diagnosis indicates the year gastric cancer was diagnosed.

Treatment refers to antisecretory therapy at the time of investigation.

investigated by barium meal within three years of the endoscopic diagnosis while two patients had had a barium study just over three and six years, respectively, prior to the endoscopic diagnosis of gastric cancer.

\section{Diagnosis}

Of 30 patients investigated by barium meal examination, nine had duodenal ulcer disease and eight had gastric ulcer as the radiological diagnosis (one patient had both). The remainder had non-specific diagnoses such as hiatus hernia or were normal. As a consequence of previous investigation, six patients had undergone gastric surgery for ulcer disease, two of whom were found to have EGC 22 years and nine years, respectively, before developing a second gastric cancer. Ten patients had a subsequent gastroscopy prior to the gastroscopy which resulted in a diagnosis of gastric cancer. The time between barium meal examination and gastroscopy was usually long. This group of patients is included in the analysis of patients having undergone gastroscopy prior to the diagnostic gastroscopy.

\section{PREVIOUS GASTROSCOPY}

All patients were eventually diagnosed at gastroscopy, but previous investigation by gastroscopy had been carried out in 20 patients. Ten of these patients had had a barium meal examination at some stage in the past. In only one case was this a follow on investigation.
Diagnosis

Gastroscopy was reported as normal in nine patients; seven patients had gastric ulcer disease, one of whom had EGC diagnosed 22 years earlier at operation for gastric ulcer. The remaining patients were diagnosed as having duodenal ulcer disease $(n=2)$ or reflux $(n=2)$.

\section{Treatment}

Eleven patients had a gastroscopy within three years of the diagnostic gastroscopy. Within this group six patients had been on an $\mathrm{H}_{2}$ receptor antagonist for more than 12 months prior to the initial gastroscopy. A further three patients had been on an $\mathrm{H}_{2}$ receptor antagonist for up to one year. Thus $82 \%$ of those patients with a previous history of dyspepsia had received some form of symptomatic treatment prior to a gastroscopy which did not reveal malignancy even though all patients were eventually found to have gastric cancer within three years. The majority had been on an $\mathrm{H}_{2}$ receptor antagonist alone or in combination with an antacid. In the whole group (20 patients), 12 patients previously investigated by gastroscopy were subsequently diagnosed as having gastric cancer within four years. All gastric ulcer patients had a follow up gastroscopy, but repeat biopsy of the ulcer site was not performed in three patients. Two patients had gastric cancer diagnosed within four years of a barium meal examination. 
Patients $(n=81)$

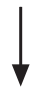

No previous dyspepsia (22 (27\%) (excluded))

Previous dyspepsia $(n=59(73 \%))$

(37 had treatment and 10 had investigation but no records of treatment)

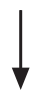

No investigation (19 excluded)

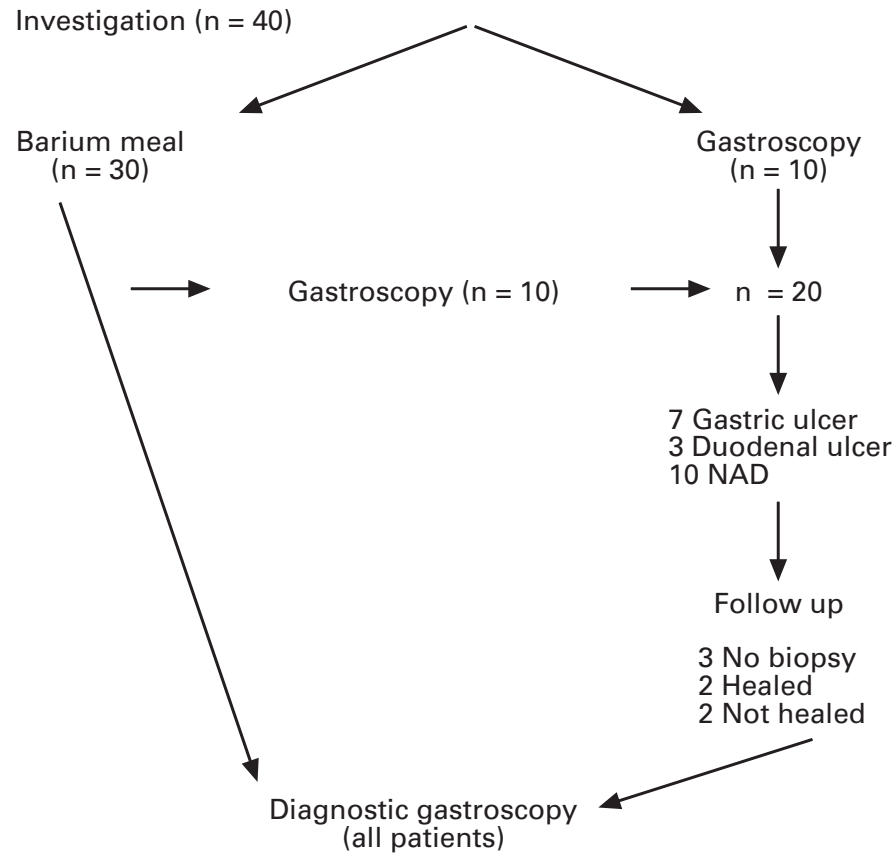

Figure 1: An overview of the past medical history of 81 patients dying of gastric cancer in the years 1991-95 (results obtained from primary care records). NAD, no abnormality detected.

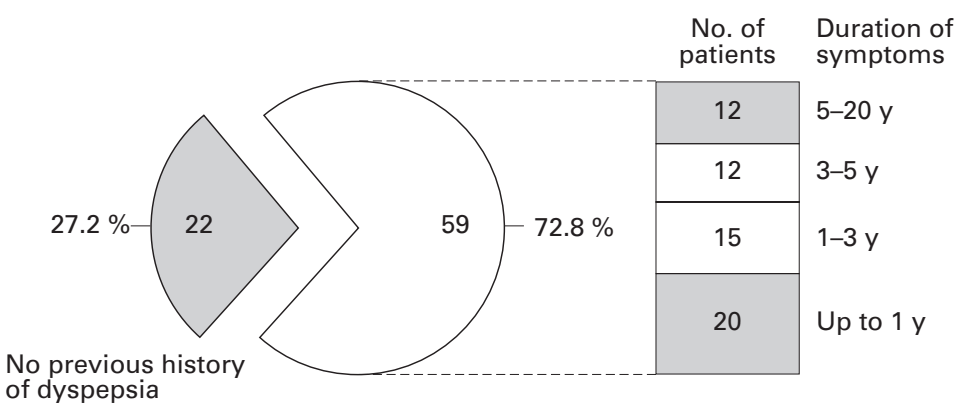

Previous history of dyspepsia

Figure 2: Durtion of symptoms in 59 patients with a previous history of dyspepsia.

OPEN ACCESS GASTROSCOPY

Only one patient had an open access gastroscopy within three years of the diagnosis of gastric cancer. The remainder were all gastroscoped following a clinic visit; no one person seemed to be missing lesions more than others. Although numbers are small OAG comes out well in terms of not appearing to miss EGC.

\section{Discussion}

Patients with gastric cancer may present with advanced disease for a whole variety of reasons not least of which might be the absence of symptoms or failure to consult the general practitioner with minor symptoms. Open access gastroscopy has been suggested as one reason why some centres are seeing an increasing incidence of EGC as opposed to more advanced disease. ${ }^{3}$ The aim of this study was to look specifically at OAG in relation to the overall incidence of gastric cancer in a district where this facility has been available for over seven years. Previous studies have either shown no benefit ${ }^{10}$ or been unable to separate OAG from conventional referral patterns. ${ }^{34}$

Although there is an encouraging trend towards more early stage disease in the OAG group which might become significant with larger numbers (type 2 statistical error), the overall incidence of early stage gastric cancer remains disappointingly low. Referral bias accounts for the higher incidence of advanced disease in the non-OAG patients, the majority of whom had worrying symptoms. This has been noted in another study. ${ }^{8}$ In order to improve the earlier detection of this disease patients must be referred when symptoms are benign. $^{7}$

The OAG group of patients were less likely to have the diagnosis suspected by the general practitioner because symptoms were more benign than in the clinic group. Increasing use of OAG for "at risk" patients with benign symptoms clearly has the potential to increase the diganosis of early disease in South Tees ( $23 \%$ for OAG) to levels reported from Leeds (26\% stage I disease) and Birmingham (26\% EGC). Unfortunately even when symptoms were worrying, general practitioners appeared reluctant to consider a diagnosis of gastric cancer. In order to improve the detection rate of EGC general practitioners must consider a diagnosis of gastric cancer when symptoms are benign. If referral is only prompted by worrying symptoms it is unlikely that further inroads will be made into diagnosing this condition earlier.

We were surprised to find such a high prevalence of lifetime dyspepsia compared with our control group; however, this agrees with previous data regarding consultation rates for dyspeptic symptoms, even though the prevalence of dyspepsia in the population is much higher than this. ${ }^{11}{ }^{12}$ It has been suggested that $60-90 \%$ of patients with EGC are symptomatic, ${ }^{713} 14$ which correlates well with the fact that only $27 \%$ of our patients had no previous history of dyspepsia. The remainder did have a previous history of upper gastrointestinal symptoms but over a quarter had had symptoms for more than 10 years. Similar figures for the incidence of dyspepsia in patients with gastric cancer emerged from a large postmarketing surveillance study of cimetidine. ${ }^{15}$ The same study also showed that well over half of the patients diagnosed as having adenocarcinoma of the stomach had been on treatment (cimetidine) for up to four years prior to diagnosis. Over $90 \%$ of these patients had advanced disease.

In this study $51 \%$ patients had been investigated previously and $28 \%$ already had an established benign diagnosis. It is highly likely that this resulted in the delay of 14 weeks 
between the patient noticing new symptoms and consulting the general practitioner. The delay in referring patients to hospital is also likely to be due to the fact that many patients had already been investigated, often within the last three to five years. This raises an important question as to whether or not these patients had EGC missed on initial endoscopy. The natural history of gastric cancer is that of a slowly progressive neoplasm which takes three to four years to go from "early" to advanced disease. ${ }^{16} 17$ The two patients previously diagnosed as having EGC only had the diagnosis made at operation when gastric ulcer was the indication for surgery. Both of these patients should have had the diagnosis suspected earlier.

It is likely that patients presenting with advanced disease within three to four years of a previous upper gastrointestinal investigation had the diagnosis of EGC missed during the first examination (one in six patients). The value of a barium meal versus gastroscopy has been previously debated, ${ }^{18}{ }^{19}$ but most endoscopists would readily accept that both examinations could miss early lesions particularly if biopsy specimens are not taken. However the scale of the problem is likely to surprise those who feel that gastroscopy is less likely than a barium meal to miss early gastric cancer. The main reason was failure of the experienced endoscopist to biopsy a seemingly benign abnormality; occasionally, it was due to inexperienced endoscopists missing a high lesion. This raises several important questions concerning the endoscopic criteria for the diagnosis of EGC, ${ }^{201}$ and suggests that in our health district the threshold for biopsying an abnormality is too high.

Examining hospital records underestimated previous investigation of upper gastrointestinal symptoms. The cumulative percentage of patients having had a previous upper gastrointestinal investigation (two barium meals, 11 gastroscopies) was $6 \%$ within one year, $12 \%$ within two years, and $16 \%$ within three years. As all these patients had advanced disease (greater than stage I) the inevitable conclusion is that they probably had the early lesion at the time they were initially investigated but that this was missed or misinterpreted as benign disease. The fact that five of these patients had gastric ulcer disease, three of which healed, emphasises the importance of not only repeat gastroscopy but also multiple biopsy of the abnormal area, ${ }^{22}$ and repeat biopsy. The data also point towards $\mathrm{H}_{2}$ receptor antagonists being a major factor in masking both the symptoms and appearance of EGC, making clinical and endoscopic diagnosis more difficult. Previous reports of mucosal healing in gastric cancer may be grossly underestimating the problem. ${ }^{23}$ It is clear from other studies that patients are often treated prior to gastroscopy and the problem is not unique to South Tees. ${ }^{24}{ }^{25}$ It is possible that the increasing use of gastroscopy is elevating the detection rate of EGC in centres where $\mathrm{H}_{2}$ receptor antagonists are prescribed less often prior to gastroscopy and that our own data simply show the adverse effect of this policy on detection rates. The increased risk of gastric cancer in the first years after starting an $\mathrm{H}_{2}$ receptor antagonist ${ }^{1526}$ indicates that patients do receive treatment prior to diagnosis and that malignant disease is being missed. At present we do not know whether low doses of $\mathrm{H}_{2}$ receptor antagonists can heal the mucosal lesion associated with EGC, but if over the counter $\mathrm{H}_{2}$ receptor antagonist usage increases and such lesions are healed by low dose treatment, the opportunity for increasing the detection rate of EGC might be compromised further.

In summary, we have shown that in South Tees Health District advanced gastric cancer is still the usual presentation with $87 \%$ of patients having greater than stage I disease. The reasons for this appear multifactorial but could be improved by better clinical practice. It could be argued that it is more important to refer patients with benign symptoms as surgical cure of gastric cancer is unlikely once worrying symptoms develop. General practitioners also need to be made more aware of the potential for antisecretory drugs to heal or mask EGC, which will then have a major detrimental impact on patient management. Guidelines for the appropriateness of gastroscopy in patients with dyspepsia ${ }^{27}$ need to reflect both the importance of not starting treatment prior to gastroscopy and the need to investigate patients again, even if they have had an established benign diagnosis several years previously.

Similarly, hospital endoscopists need to be made more aware of the reasons why EGC is being missed, as we believe it is. More supervision for inexperienced endoscopists and a lower threshold for biopsying any abnormality are essential prerequisites to improving the detection rate of earlier stage disease.

Dr Z Suvakovic was supported by a grant from the Astra Foundation and The South Tees Gastroenterology Research Fund Preliminary data were presented to the September meeting of the British Society of Gastroenterology at Warwick in 1995.

1 Thompson GB, van Heerden JA, Sarr MG. Adenocarcinoma of the stomach: are we making progress? Lancet 1993; 342: 713-8.

2 Allum WH, Powell DJ, McConkey CC, Fielding JWL. Gastric cancer: a 25 year review. Br f Surg 1989; 76: 535-40.

3 Sue-Ling HM, Johnston D, Martin IG, Dixon MF, Lansdown MRJ, McMahon MJ, Axon ATR. Gastric cancer: a curable disease in Britain. BMf 1993; 307: 591-6.

4 Hallissey MT, Allum WH, Jewkes AJ, Ellis DJ, Fielding JWL. Early detection of gastric cancer. BMF 1990; 301: 513-5.

5 Houghton PJW, Mortensen NJMcC, Allan WH, Ellis DJ, Williamson RCN, Davies JD. Early gastric cancer; the case for long term surveillance. BMF 1985; 291: 305-8.

6 Bramble MG, Cooke WM, Corbett WA, Cann PA, Clarke D, Contractor B, Hungin AS. Organising unrestricted open D, Contractor B, Hungin AS. Organising unrestricted op

7 Fielding JWL, Ellis DJ, Jones BG, Paterson J, Powell DJ, Fielding JWL, Ellis DJ, Jones BG, Paterson J, Powell DJ,
Waterhouse JAH, Brookes MVS. Natural history of "early" gastric cancer: results of a 10 year regional survey. $B M \mathcal{F}$ 980; 281: 965-7.

8 Kerrigan DD, Brown SR, Hutchinson GH. Open access gastroscopy: too much to swallow. BMF 1990; 300: 374-6. 9 Kennedy BJ. The unified international gastric cancer staging classification. Scand f Gastroenterol 1987; 22 (suppl 133): 11-3.

0 Holdstock G, Bruce S. Endoscopy and gastric cancer. Gut 1980; 22: 673-6.

11 Jones R, Lydeard S. Prevalence of symptoms of dyspepsia in the community. BMF 1989; 298: 30-2.

12 Jones RH, Lydeard SE, Hobbs FDR, Kenkre JE, Williams EI, Jones SJ, et al. Dyspepsia in England and Scotland. Gut 1990; 31: 401-5.

13 Lawrence M, Shiu MH. Early gastric cancer: twenty eight year experience. Ann Surg 1991; 213: 327-34.

14 Longo WE, Zucker KA, Zdon MJ, Modlin IM. Detection of early gastric cancer in an aggressive endoscopy unit. $\mathrm{Am}$ Surg 1989; 55: 100-4. 
15 Colin-Jones DG, Langman AJS, Lawson DH, Logan RFA, Paterson KR, Vessey MP. Post-cimetidine surveillance for up to ten years: incidence of carcinoma of the stomach and oesophagus. $Q$ f Med 1991; 285: 13-9.

16 Tsukuma H, Mishima T, Oshima A. Prospective study of early gastric cancer. Int f Cancer 1983; 31: 421-6.

17 Eckardt VF, Willems D, Kanzler G, Remmele W, Bettendorf U, Paulus W. Eighty months persistence of poorly differentiated early gastric cancer. Gastroenterology 1984; 87 719-24.

18 Dooley CP, Weiner JM, Larson AW. Endoscopy or radiology? The patient's choice. Prospective comparative
survey of patients acceptibility of upper gastrointestinal endoscopy and radiology. Am F Med 1986; 80: 203-7.

19 Rogers IM, Sokhi GS, Moule B, Joffe SN, Blumgart LH. Endoscopy and routine and double-contrast barium meal in diagnosis of gastric and duodenal disorders. Lancet

20 Ballantyne KC, Morris DL, Jones JA, Gregson RH, Hardcastle JD. Accuracy of identification of early gastric Hardcastle JD. Accuracy of identific
cancer. Brf S Surg 1987; 74: 618-9.
21 Misumi A, Misumi K, Murakami A, Harada K, Honmyo U, Akagi M. Endoscopic diagnosis of minute, small, and flat early gastric cancers. Endoscopy 1989; 21: 159-64.

22 Ito Y, Blackstone MO, Riddell RH, Kirsner JB. The endoscopic diagnosis of early gastric cancer. Gastrointest Endosc 1979; 25: 96-101.

23 Taylor RH, Menzies Gow N, Lovell D, La Brooy SJ, Misiewicz JJ. Misleading response of malignant gastric ulcers to cimetidine. Lancet 1978; i: 686-8.

24 Gear MWL, Wilkinson SP. Open access upper alimentary endoscopy. Br f Hosp Med 1989; 41: 438-44.

25 Hallisey MT, Fielding JWL, Allum WH, Ellis DJ. Managing dyspepsia. Lancet 1987; i: 1533-4.

26 Moller H, Nissen A, Mosbech J. Use of cimetidine and other peptic ulcer drugs in Denmark 1977-1990 with analysis of the risk of gastric cancer amongst cimetidine users. Gut 1992; 33: 166-9.

27 Axon ATR, Bell GD, Jones RH, Quine A, McCloy RF. Guidelines on appropriate indications for upper gastrointestinal endoscopy. BMF 1995; 310: 853-6. 